\title{
How Can Libraries Improve Wikipedia?
}

\section{Eric Phetteplace}

Correspondence concerning this column should be addressed to Eric Phetteplace, Systems Librarian, California College of the Arts, 5212, Broadway, Oakland, CA 94618; email:ephetteplace@cca.edu.
W ikipedia and libraries got off to a strained start. Perhaps this is only my perception, but it appeared that Wikipedia was used as a defenseless punching bag in much information literacy instruction. ${ }^{1}$ The refrain was always "don't use Wikipedia" or "don't use Google" to the neglect of far worse research sources like Yahoo! Answers. This "traditional" stance of librarianship was that the community-edited encyclopedia failed any quality analysis due to its sketchy authority; "anyone can edit" — anonymously even! — and therefore its content cannot possibly be trusted. Instructors would even develop assignments wherein students would vandalize the encyclopedia, deliberately inserting inaccurate or incoherent content, to demonstrate its unreliability. Leaving ethics aside, such assignments are constructed to ignore the finely tuned "bots" (editing programs which constantly crawl the site looking for clear signs of mischief) and diligent editors working to remove such content.

A more balanced view shows that Wikipedia, while imperfect, is a strong source of information. I used to employ the aptly named "CRAAP" test when teaching information literacy and Wikipedia's test results are informative:

Currency-Wikipedia articles are often updated frequently, with current events being reflected almost immediately. This standard is a great chance to show students the "View history" tab of each article which lists all edits in reverse chronological order.

Relevance-Wikipedia's incredible scope virtually ensures it has something pertinent no matter the research topic. This is one area where the online encyclopedia indubitably outshines some of its more historied competitors.

Authority—The first "A" is where Wikipedia obviously fails according to CRAAP; its authors can be inexpert, and sometimes unknown or anonymous.

Accuracy_-Wikipedia articles emphasize sourcing every statement and can include hundreds of references.

Purpose-Wikipedia is run by a nonprofit organization and devoted to the free spread of information, much like libraries. It fares quite favorably compared to many other web sources in this regard. 
Making first- or second-year students actually perform the analytical work to come to the conclusion that Wikipedia is strong in some respects but weak in others is a huge victory. Better than simply blacklisting particular resources, students will know why it is inappropriate to use in particular contexts. The encyclopedia itself admits as much, stating that "in most academic institutions Wikipedia, like most encyclopedias and other tertiary sources, is unacceptable as a source for facts in a research paper" on a page about using Wikipedia for research. ${ }^{2}$ I also like to point out that Wikipedia is a rare source that warns the reader about its own inconsistencies. There are large, loud boxes at the top of flawed articles calling attention to their issues: "The neutrality of this article is questioned because of its systemic bias," "This article needs additional citations for verification," "This article's factual accuracy is disputed."

I'm sure many librarians have come to recognize Wikipedia's value and sport a more positive opinion. While the site is not flawless, its articles are often of similar quality as ones from more established reference sources. Famously, Nature performed a comparison of scientific articles and found Wikipedia to be comparable to Encyclopaedia Britannica. ${ }^{3}$ Following the study, a community project to correct the identified errors in Wikipedia sprung up, fixing them all in a little over a month. ${ }^{4}$ Wikipedia's veracity aside, it also shares some values with libraries, as noted in the "Purpose" section above. It is, essentially, devoted to the free distribution of knowledge. Sound familiar? It is little wonder that libraries have found Wikipedia to be a valuable partner in publicizing our content. Articles like "Using Wikipedia to Extend Digital Collections," "Putting the Library in Wikipedia," and "Wikipedia Lover, Not a Hater: Harnessing Wikipedia to Increase the Discoverability of Library Resources" all discuss the value of working with Wikipedia to highlight library digital collections and metadata. $^{5}$

A good example of Wikipedia driving traffic to library special collections was brought to my attention by my colleague Margaret Heller, Digital Services Librarian at Loyola University Chicago, who pointed me toward the Google Analytics Usage Reports for the Consortium of Academic and Research Libraries in Illinois (CARLI) Digital Collections. CARLI regularly records Wikipedia as one of the top external traffic sources, with Wikipedia being noted in the last few quarterly reports as a traffic source leading "to home pages or images from multiple CARLI Collections." "

However, this column is not a paean to Wikipedia. Rather, I'd like to revisit one of the five pillars of Wikipedia; "Wikipedia is written from a neutral point of view." The concept of neutrality has been under fire from critical librarians lately. ALA Annual featured a well-attended presentation titled "But We're Neutral!" And Other Librarian Fictions Confronted by \#critlib. A seminal article appearing earlier this year in Code4Lib Journal by Bess Sadler and Chris Bourg began with a section labelled "Libraries are not Neutral":
Despite the pride many libraries take in their neutrality, libraries have never been neutral repositories of knowledge. Research libraries in particular have always reflected the inequalities, biases, ethnocentrism, and power imbalances that exist throughout the academic enterprise through collection policies and hiring practices that reflect the biases of those in power at a given institution. In addition, theoretically neutral library activities like cataloging have often recreated societal patterns of exclusion and inequality. ${ }^{7}$

Turns out, Wikipedia has much the same problem; while it appears neutral on the surface, its topical coverage and treatment of subjects reflect the power relations of our society. A 2011 study found that 91 percent of editors were men. The same study shows that few editors come from the Global South and that the English Wikipedia receives far more focus than other languages. Another research paper from 2011 goes a bit further in demonstrating that "male articles are significantly longer than female articles." ${ }^{8}$ Thus the editorial gender gap has real effects on the encyclopedic content; it's not just that having editors of all genders is good in its own right, it's that Wikipedia's claims to objectivity and neutrality are jeopardized by the disbalance.

It should now be evident that the ways that library's highlight their institutional content in Wikipedia only exacerbates this issue. If libraries and archives have content that privileges the dominant point of view, and we attempt to surface that content by linking to it within Wikipedia, we only further skew the already lopsided coverage. Our intentions are to highlight interesting, possibly even neglected, materials sitting in our digital repositories. But are we doing that at the cost of historically marginalized peoples and topics? Are we surfacing art depicting the Detroit race riots or the manuscripts of a dead white man? ${ }^{9}$ We have a choice in what we choose to publicize and assuming that all content is of equal importance only solidifies the status quo.

\section{ART+FEMINISM EDIT-A-THON}

So what is a librarian to do? There are several Wikipedia projects focused on recruiting editors from underrepresented groups and addressing lackluster coverage of particular topics which libraries and librarians can support. Let's look at one such project, Art+Feminism. In its own words:

Art+Feminism is a rhizomatic campaign to improve coverage of women and the arts on Wikipedia, and to encourage female editorship. . . The reasons for the gender gap are up for debate: suggestions include leisure inequality, how gender socialization shapes public comportment, and the contentious nature of Wikipedia's talk pages. The practical effect of this disparity, however, is not. Content is skewed by the lack of female participation. Many articles on notable 
women in history and art are absent on Wikipedia. This represents an alarming aporia in an increasingly important repository of shared knowledge. ${ }^{10}$

Art+Feminism started by hosting an edit-a-thon out of the Eyebeam Art and Technology Center in New York City in 2014, with more than thirty other locations joining in worldwide. An edit-a-thon is an event where people congregate to perform Wikipedia edits, often centered around a particular theme or project. Institutions of higher education and libraries make perfect partners for such occasions. We typically have useful materials to be cited and our students form a large body of potential participants who can be easily incentivized to join in, whether with extra credit or free food. When my library heard of the upcoming second annual edit-a-thon, we immediately began planning to host it.

First, we set up a meetup page on Wikipedia. If you are unfamiliar with Wikipedia, creating a page like this is not a struggle. For one, you can simply copy the entire source markup of someone else's meetup, then edit your specific details into that skeleton. For two, you can enable the experimental Visual Editor to make Wikipedia even easier to edit without learning Yet Another Markup Language. ${ }^{11}$ The meetup page is an important place for putting up information like timing and directions, but is also a place for us to talk about the impact we made by showing how many editors attended and what articles we improved or created.

While we were putting initial details on our meetup page, we set about securing a location on the date of the edit-a-thon. We discovered that a gallery associated with our school had hosted the edit-a-thon the prior year, but they were unable to repeat it. Our school has campuses in both San Francisco and Oakland, but since Oakland had no other edit-a-thon locations we decided to host it in that city with the idea that people local to San Francisco already had an event nearby.

One of the better ways libraries specifically can aid an edit-a-thon is by providing materials focused in on the theme. A library staff member went through our collection, pulling volumes either by or about female artists. These volumes can then be a bountiful source of references for articles. While much has been digitized and made available online, virtually every library has titles with information that cannot be found on the web. These print works fill in vital gaps and provide sound sources on which to build articles. Library databases help in much the same way; we can highlight particular subject databases which are likely to contain relevant but paywalled articles that the public might not otherwise have access to.

Related to providing library materials for editors to use is reference assistance. Even with all the right information at hand, citation chasing or effectively navigating a text (e.g., with the use of indexes, abstracts) is alien to many people. These are places where librarians are naturally trained to help. We can identify an information need and use our skills to help editors find the best content available. But we should caution ourselves to not assume that, as information professionals, we are Wikipedia experts as well. Wikipedia has its own authorial style, community norms, editing interface, and unique quirks. Knowing how to properly cite a podcast in APA style does not equate to knowing how to use the work in an article. Instead, it is strongly recommended that edit-a-thons recruit experienced editors to assist during the event. For our event, I looked at a local WikiProject and put out a call for help on the "Talk" page. A couple editors contacted me afterward and one attended our event. Second, the Wikimedia Foundation that runs Wikipedia often supports events and sends staff to them. After we corresponded with the people coordinating Art+Feminism in the Bay Area, someone from the Foundation agreed to attend and even gave a brief warm-up talk at the beginning on how to write articles that withstand scrutiny.

All the points mentioned above were the key ingredients in bringing everyone together: securing a space, selecting topical materials, and convincing experienced editors to join us. On the day of, however, there was still some work to be done to ensure the event was a success. The Art+Feminism project recommended giving all attendees color-coded name badges which denoted their comfortability with being photographed: red meant no pictures, orange meant please ask for permission, and green was a go-ahead. We took a few pictures during the day and shared them via social media, using \#ArtAndFeminism. These acts ensure the event is publicized and that everyone is copacetic.

While our attendance was modest, featuring primarily library staff members, we achieved quite a lot of work: editors touched fourteen different articles, uploaded six images to Wikimedia Commons, and performed over a hundred and fifty individual edits. We intend to build on those results in the coming year, advertising more and reaching out to interested campus groups in an attempt to increase attendance. Many of our faculty expressed interest in the event, going so far as to offer extra credit to students who attended, but we can integrate Wikipedia editing even further into courses by making it a portion of graded assignments.

We did have one negative experience, when an image uploaded to Wikimedia Commons for use on a page was flagged for deletion. The editor flagging it said something along the lines of "this isn't your personal photo album" as the image was a headshot of a female artist. In the ensuing deletion discussion, I noted that the image was about to be used on an article and it was never removed from Commons. Still, the incident underscores cultural problems in Wikipedia. The confrontational style of the deletion discussion lacked good faith. ${ }^{12}$ Further, I saw a gendered undertone in the editor's response; how many pictures of white men are derided as personal photos? While our library staff person was undeterred, it's these moments of hostility that drive away newcomers.

Events like the Art+Feminism edit-a-thon are exactly what libraries should be supporting. We are going outside the walls of the library, affecting incredibly popular content 


\section{ACCIDENTAL TECHNOLOGIST}

used by multitudes. We are doing so within community guidelines, as partners with volunteer editors and Wikimedia, and not on our own. Rather than resigning ourselves to the current prejudiced circumstances, we are actively working to combat them. There is doubtless much work to be done, and Wikipedia is hardly the only place on the web that needs efforts like this, but it's a start.

\section{References}

1. Please forgive me the straw person argument here. I feel it's illustrative to characterize a certain negative attitude toward Wikipedia among librarians, even if I must admit I have no empirical evidence that this is at all common or ever was. Is a research survey in order?

2. "Wikipedia: Researching with Wikipedia," Wikipedia, the Free Encyclopedia, 2014, https://en.wikipedia.org/ w/index.php?title=Wikipedia:Researching_with_Wikipedia \&oldid $=629003624$.

3. Jim Giles, "Internet Encyclopaedias Go Head to Head" Nature 438, no. 7070 (2005): 900-901, http://dx.doi.org/10.1038/438900a.

4. For Wikipedia's internal take on the correction process, see "Wikipedia: External Peer Review/Nature December 2005," Wikipedia, the Free Encyclopedia, 2012, https://en.wikipedia .org/w/index.php?title=Wikipedia:External_peer_review/ Nature_December_2005\&oldid=524721916. A study similar to Nature's is Jona Kräenbring et al., "Accuracy and Completeness of Drug Information in Wikipedia: A Comparison with Standard Textbooks of Pharmacology." PLoS ONE 9, no. 9 (2005): e106930, http://dx.doi.org/10.1371/journal.pone.0106930.

5. Ann M. Lally and Carolyn E. Dunford, "Using Wikipedia to Extend Digital Collections," D-Lib Magazine 13, no. 5/6 (2007), http://dx.doi.org/10.1045/may2007-lally; Lauren Pressley and Carolyn J. McCallum, "Putting the Library in Wikipedia," ONLINE Magazine (September 2008), https://wakespace.lib.wfu .edu/handle/10339/31874; Danielle Elder, R. Niccole Westbrook, and Michele Reilly, "Wikipedia Lover, Not a Hater: Harnessing Wikipedia to Increase the Discoverability of Library Resources," Journal of Web Librarianship 6, no. 1 (2012): 32-44, http://dx.doi .org/10.1080/19322909.2012.641808

6. "Google Analytics Usage Reports for CARLI Digital Collections I CARLI," Consortium of Academic and Research Libraries in Illinois, 2015, www.carli.illinois.edu/products-services/contentdm/google-analytics-usage-reports-carli-digital-collections.

7. Bess Sadler and Chris Bourg, "Feminism and the Future of Library Discovery," The Code4Lib Journal 28 (April 2015), http:// journal.code4lib.org/articles/10425.

8. Shyong (Tony) K. Lam et al., "WP:Clubhouse?: An Exploration of Wikipedia's Gender Imbalance," in Proceedings of the 7th International Symposium on Wikis and Open Collaboration (New York: ACM, 2011), 1-10, http://dx.doi.org/10.1145/2038558.2038560. http://files.grouplens.org/papers/wp-gender-wikisym2011.pdf. I am skeptical of how "male" and "female" articles were defined, but the paper itself is thorough in its argumentation and statistical analysis. It is also worth noting that this paper, and much of the other literature around the gender gap, ignores genders outside the female-male binary. More accurately, the gap can be defined as a disproportionate majority of males, as opposed to a minority of females, which leaves all other genders out of the picture

9. Robert Clark Templeton, Race Riots, Detroit: Twelfth Street, Detroit, 1967, pastel on paper, National Portrait Gallery, http://col lections.si.edu/search/results.htm?q=record_ID\%3Anpg_NPG. 78.TC167\&repo=DPLA

10. "Wikipedia: Meetup/ArtAndFeminism," Wikipedia, the Free Encyclopedia, 2015, https://en.wikipedia.org/w/index.php?title =Wikipedia:Meetup/ArtAndFeminism\&oldid $=676121837$.

11. There actually is a text format called YAML, an abbreviation for Yet Another Markup Language.

12. For more on the importance of good faith when editing Wikipedia, see Joseph Reagle, "Good Faith Collaboration: The Culture of Wikipedia," 2015, http://reagle.org/joseph/2010/gfc. 